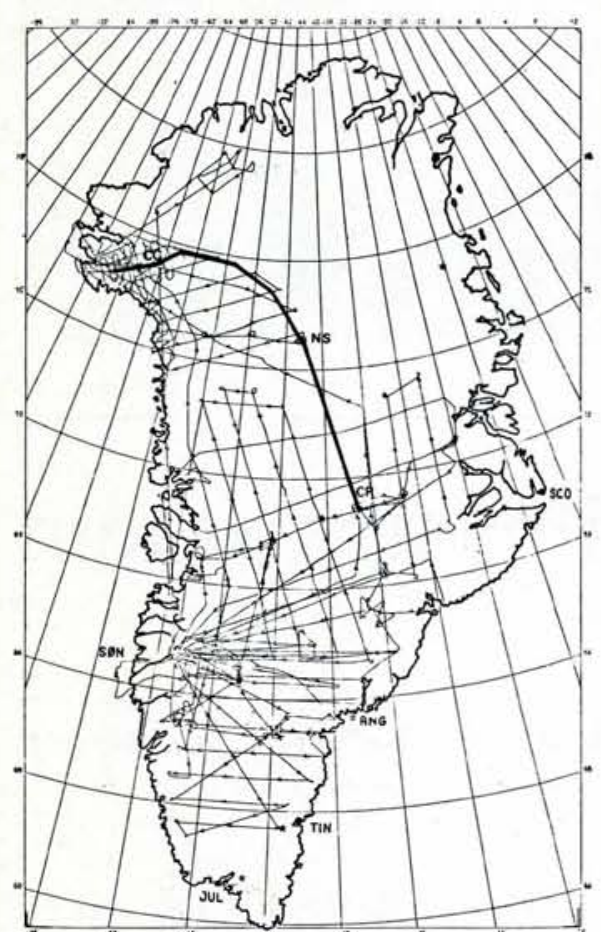

Fig. 1. Map of Greenland with flight lines drawn by computer. The thick line refers to the profile of Fig. 3 with the ice stations: $C C=$ Camp Century, NS = North Site and $C R=$ Crête.

Radio echo sounding has been used for a number of years in the exploration of polar ice such as the inland ice in Greenland and Antarctica. By means of this technique a number of important glaciological and geophysical parameters may be determined. Examples are ice thickness, bedrock topography and structure, stratification patterns which are used for climate and flow patterns studies, and ice velocity measurements. The technique now constitutes a very important tool in the investigations of the large polar areas covered by ice.

This article describes by way of example the airborne radio echo sounding carried out in Greenland by the Technical University of Denmark (TUD).

\section{Greenland Investigations}

During six seasons since 1968 more than $60000 \mathrm{~km}$ of flight lines have been sounded by TUD. Fig. 1 is a computer drawing of executed flight lines based on automatic recordings of positions determined by the inertial navigation system on board the $\mathrm{C}-130$ aircraft employed.

The soundings were carried out by means of special low-frequency pulse radar systems at $60 \mathrm{MHz}$ and 300 $\mathrm{MHz}$ developed at TUD. The choice of frequency is based on the following considerations. A frequency above $30 \mathrm{MHz}$ should be chosen in order to

\title{
Radio Echo Sounding of the Greenland Inland Ice
}

\section{P. Gudmandsen and G. H. Jakobsen, Lyngby}

(Electromagnetics Institute, Technical University of Denmark)

avoid interference problems due to long-distance ionospheric propagation and a high frequency is desirable to arrive at a practical size of radar antenna. Also at high frequency, better spatial resolution is obtained for a given antenna size. However, the frequency should be below about 500 $\mathrm{MHz}$ in order to take advantage of the low-loss properties of the ice. An essential part of the TUD radioglaciological programme has been devoted to a continuing development of equipment and measuring techniques to cope with phenomena - practical as well as geophysical - encountered during field operations.

\section{Radio Echo Sounding Technique}

The implication of the radio echo sounding technique may be described by means of the $60 \mathrm{MHz}$ recording shown in Fig. 2. The two photos in the upper part of the figure show the received signals at a time interval of $15 \mathrm{~s}$ corresponding in this case to a distance of $1.2 \mathrm{~km}$. The signals observed are - counted from the left : - (a) the short transmitted pulse (100 ns) which leaks into the receiver, (b) the wide pulse signal reflected from the ice surface on which are superimposed a number of small pulses in particular on the decaying part of the pulse, and (c) the echo from the bedrock.
In addition to these "snapshots" of the signals, simultaneous recording is made on a continuous moving film of the signals displayed on an oscilloscope in an intensity modulated format. The lower part of Fig. 2 shows a short part of such a film where (a) the upper horizontal line is the transmitted pulse (the position of the aircraft), (b) the next line is the ice surface, the aeroplane flying $250 \mathrm{~m}$ above the ice, and (c) the solid curved line is the bedrock echo.

The thin lines appearing in the ice are caused by stratification which in this case gives the small echoes superimposed on the surface echo, as mentioned above. About 16 layers are observed in the left part of the picture with two strong echoes at $385 \mathrm{~m}$ and $480 \mathrm{~m}$ which are also clearly visible in the signal representation in the upper left corner. It is noticed that the layering becomes thinner over the crest of "the hill" where the ice thickness changes from about $1200 \mathrm{~m}$ to $800 \mathrm{~m}$ and that only the strong echoes are clearly visible. The echoes below the bedrock echo line are due to the rough bedrock surface seen at an angle in the fore-and-aft direction where the antenna pattern is very wide.

The measurements are carried out with a pulse width of 100 ns and a receiver bandwidth of $14 \mathrm{MHz}$. Thus, the
Fig. 2. Recording examples obtained at $60 \mathrm{MHz}$ with a pulse width of 100ns and a receiver bandwidth of $14 \mathrm{MHz}$.

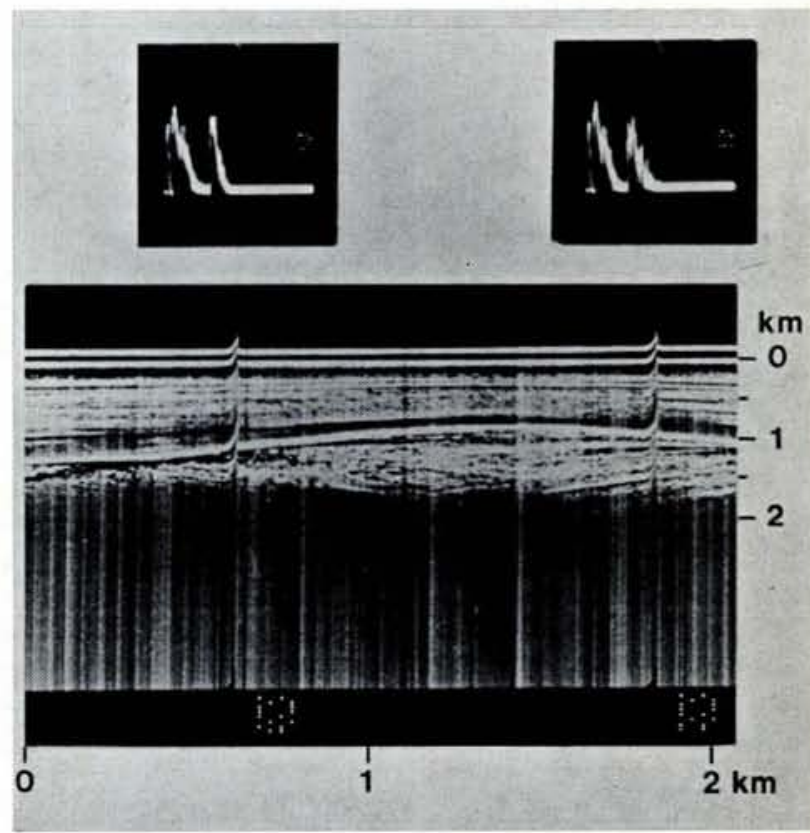


Fig. 3. Profile of the inland ice along the flight line from Thule to Crête. The numbers on the distance scale are identification numbers in the recording and data processing. Recording examples from Nos. 220 and 650 are shown in subsequent figures.

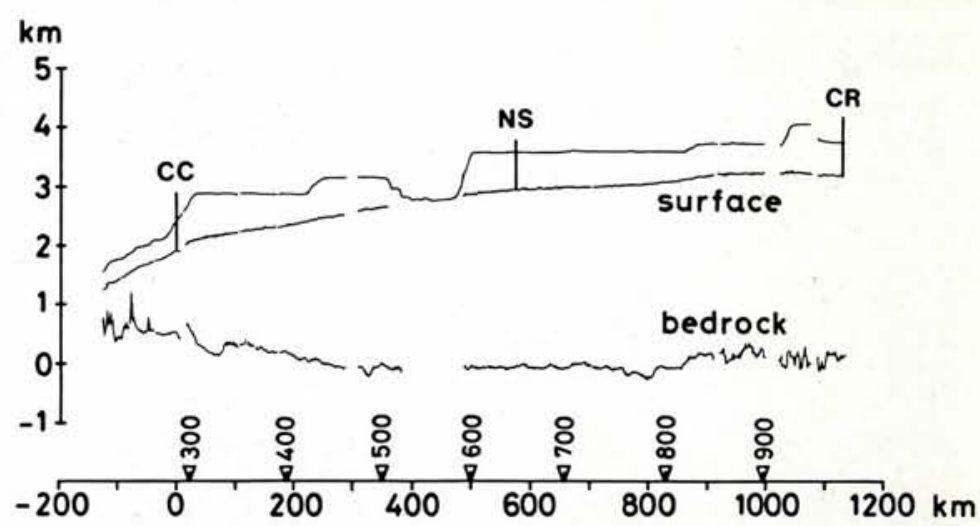

range resolution is determined by the grain size of the cathode ray tube of the recording oscilloscope employed and is about $40 \mathrm{~m}$.

\section{Ice Profile along a Flight Line}

In the data processing, the intensity modulated film recordings are digitized by means of a semi-automatic procedure and fed into a computer together with navigational data comprising position coordinates and aeroplane altitude based on the pressure altimeter on board. Correspondence between film and navigation data is ensured by means of labels introduced at data recording.

Fig. 3 is a computer drawing of a profile obtained in this way. It originates from the flight line (drawn in the thick line in Fig. 1) from Thule along the ice divide to the centre of the ice cap at Station Crête. The three lines in Fig. 3 are (a) the aeroplane position, (b) the surface contour, and (c) the bedrock, all referred to sea level. Fig. 3 shows that the bedrock is at, or below sea level over a great part of the profile in central Greenland. It is relatively smooth over long distances with mountains at the beginning of the profile and a "rolling

Fig. 4. $60 \mathrm{MHz}$ recording example from the beginning of the Thule-Crête profile. The distance is measured from Camp Century. terrain" north of Crête. It is seen that the ice dome summit is situated approximately $80 \mathrm{~km}$ north of Crête, and that an increase in the surface elevation at about No. 850 apparently is connected with the rise of the bedrock. The bedrock has two check points : at Camp Century (CC) where a core drilling through the ice was accomplished in 1966 and at Crête (CR) where seismic measurements have been made. The surface has three check points : at Camp Century, North Site (NS), and Crête where satellite fixes have been made.

Profiles like that shown in Fig. 3 are used for checking the data as a step in the procedure in the construction of a contour map of the bedrock under the inland ice. This work is in progress.

\section{Layer Echoes}

In Fig. 2 it was seen that the radar recordings reveal many details in addition to the ice thickness. As a further illustration a $60 \mathrm{MHz}$ recording from the beginning of the previous profile is presented in Fig. 4 (identification No. 220). This is a special reproduction of the original recorder film which is compressed in the flight direction while being enlarged in the vertical direction. It is a mountainous area which has a great influence on the ice as can be seen from the deformation of the stratification. At $90 \mathrm{~km}$ a peculiar feature is seen which is due to a focusing effect in the stratified surface of the ice where it is weakly undulating and taking the shape of the underlying bedrock. The hyperbolic shape of some of the mountains is an effect of the large fore-and-aft viewing angle of the antenna system. This effect may be removed in the data processing.

Another example of recording from the profile is shown in Fig. 5 (identification No. 650). It is a $60 \mathrm{MHz}$ recording from the area north of the summit with $3000 \mathrm{~m}$ of ice. The main feature of the recording is the stratification observed to depths of 2500 $\mathrm{m}$. These layer echoes extend almost continuously over hundreds of kilometres and thus seem to define time horizons of importance for the study of the history of the inland ice.

The layer echoes are due to changes in the complex permittivity of the ice. It has been proposed that the echoes are caused by (a) changes in the ice density in the vertical direction, (b) gross changes in the crystal orientation, or (c) changes in the impurity content causing changes in the loss tangent. All of these proposals are plausible - individually or combined. It seems, however, that the explana-

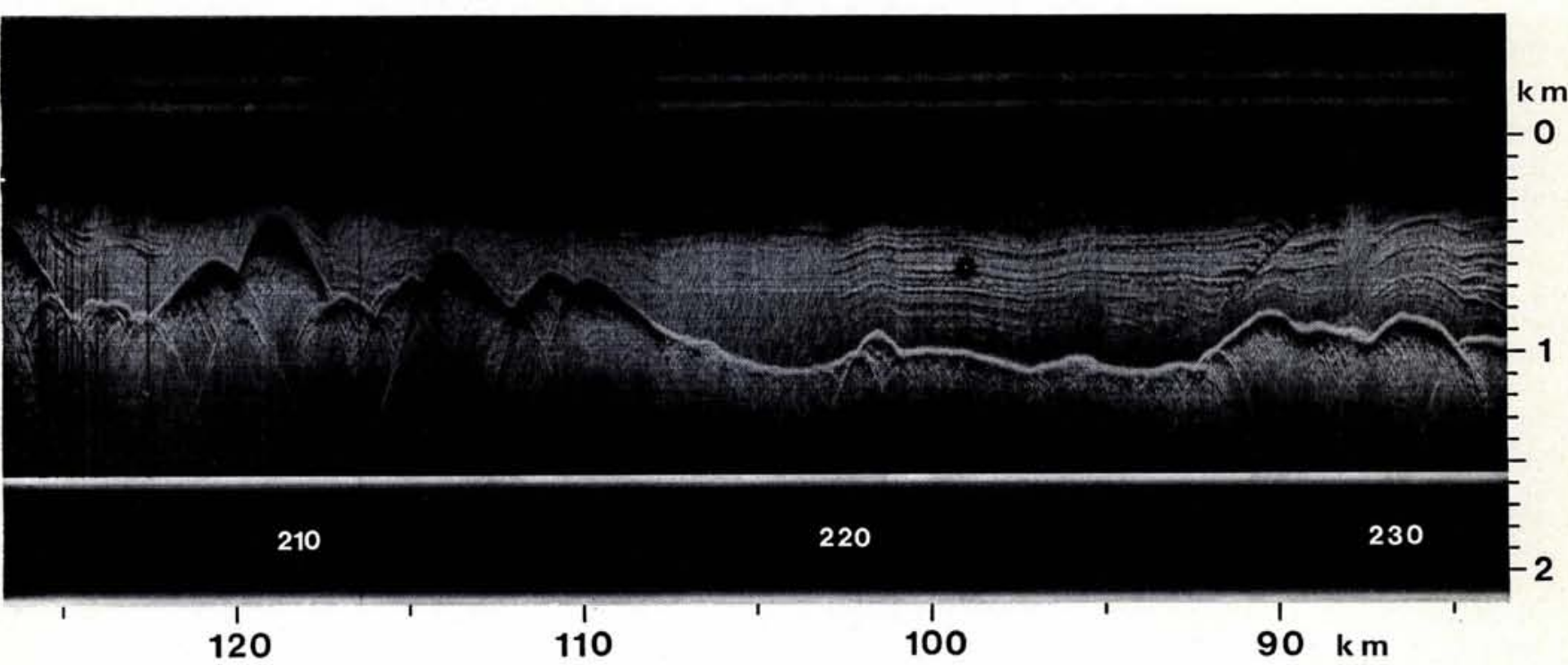




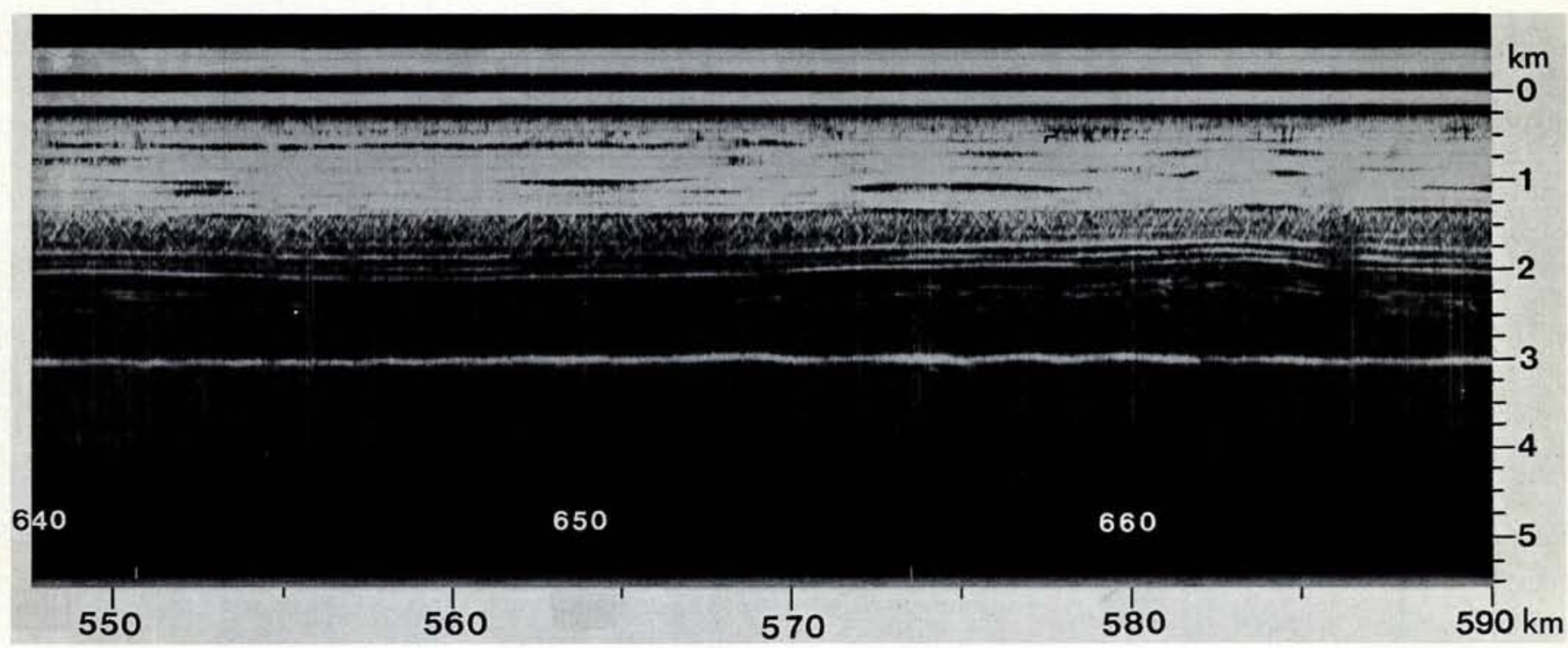

tion will remain an open question until a good correlation has been found between the radar data and ice core data from deep-hole drilling. Since this correlation is dependent on the resolution and the absolute accuracy in the determination of the individual layers it is a challenge to the radar engineer.

The resolution problem may be resolved by using a radar with a shorter pulse than at present, but this creates a sensitivity problem so that only the top layers - down to $1000 \mathrm{~m}$, for instance - may be detected with practical systems. The problem associated with the accuracy of the measurement of the absolute position of a layer seems more difficult to solve. This measurement is dependent upon a combination of geophysical and radar system parameters in connection with the definition of the detection threshold of the layer echo pulse.

Still, a third problem may be the accuracy of the measurement of the permittivity variation of the layer when localized, since the variations needed to cause the right order of reflection coefficient is very small.

\section{Stratification and Climatological Considerations}

The stratification in Fig. 5 is clearly divided into three groups. The top group of layers extends to about 1300 $m$ whilst after an interval with no layer echoes, a smaller group of layers appears and further down still another group.

The detection of a particular layer echo is a question of the sensitivity of the radar system as mentioned above. With the present system echoes with a reflection coefficient in the range of $-70 \mathrm{~dB}$ to $-90 \mathrm{~dB}\left(10^{-7}\right.$ to $\left.10^{-9}\right)$ may be detected depending upon the depth of the layer and the ice absorp- tion (ice temperature). It may therefore be possible that layers are present in the "gaps" but that their reflection coefficient is so small that it cannot be detected with the present systems. Part of the equipment design programme of TUD has been directed towards that problem. The present system is believed to be the most sensitive available and it will require a substantial effort to achieve a major improvement.

However, the radar data have been referred to data from the drill core which was recovered at Camp Century. The core data gives information about the content of the stable isotope ${ }^{18} \mathrm{O}$ as a function of depth, the content of ${ }^{18} \mathrm{O}$ being a measure of the temperature at the time of precipitation. From this comparison it is clear that the upper group of layers originates from the period following the last ice age - the holocene - the deepest of these layers having been deposited about 11000 years ago.

\section{Resolution}

It is seen that the resolution in Fig. 5 is rather coarse. In the radar system employed there is a trade-off between resolution and sensitivity and in order to detect the deep layers it was adjusted for maximum sensitivity, i.e. a pulse width of $1 \mu \mathrm{s}$ and a receiver bandwith of $1 \mathrm{MHz}$. The range resolution in the ice is therefore about $160 \mathrm{~m}$.

However, the less sensitive radar system at $300 \mathrm{MHz}$ was operated simultaneously and reveals the stratification in the upper part of the ice. The radar operates with a pulse width of $60 \mathrm{~ns}$ and a receiver bandwith of $14 \mathrm{MHz}$.

At $300 \mathrm{MHz}$ an improved angular resolution is obtained due to the confined radiation pattern of the antenna system achievable at this frequency
Fig. 5. $60 \mathrm{MHz}$ recording example from the Thule-Crête profile at North Site (NS). The distance is measured from Camp Century.

for an airbone installation. In the TUD systems the fore-and-aft radiation is about $100^{\circ}$ at $60 \mathrm{MHz}$ while it is only $35^{\circ}$ at $300 \mathrm{MHz}$. This feature is of importance when measurements are carried out in areas with crevasses, near to ice-free areas and in glacier valleys. In these cases scattering from far-distant objects on the ice surface masks the weak stratification echoes, but also often bedrock echoes, when observed at $60 \mathrm{MHz}$ while this is not the case at $300 \mathrm{MHz}$.

In a large area of southwest Greenland sounding has so far been unsuccesful due to scattering from ice lenses (refrozen melt water of relative large horizontal extent) in the ice volume seen by the antenna. In this area the sensitivity of the $300 \mathrm{MHz}$ is insufficient to overcome the absorption in this rather warm ice. An essential improvement of the $300 \mathrm{MHz}$ is therefore considered.

\section{Conclusions}

The work carried out by TUD has been performed in connection with international glaciological programmes such as the Expédition Glaciologique Internationale au Groenland (EGIG) and the Greenland Ice Sheet Program (GISP). Some of the equipment development has been carried out as part of a cooperative programme between the National Science Foundation, Washington D.C., the Scott Polar Research Institute, Cambridge, England, and TUD, with a view to antarctic investigations. The work has been supported by Danish, French, German and Swiss research foundations, by the Ministry of Greenland and National Science Foundation. 